\title{
Attitudes Toward Gays and Lesbians Among Undergraduate Social Work Students
}

\author{
Eric Swank' and Lisa Raiz²
}

\begin{abstract}
This article identifies the factors behind students' attitudes toward lesbian and gay individuals on the basis of the responses of 575 heterosexual undergraduates from 12 social work programs in the United States. Consistent with attribution theory, the findings suggest that the belief that sexual orientation is a choice is the strongest predictor of responses to gays and lesbians. The precepts of social learning theory and the intergroup contact hypothesis were also substantiated because sexual prejudice was lower among students with "gay-friendly" parents and numerous interactions with homosexual peers. Finally, negative interpretations of gay men and lesbians were higher for students who embraced authoritarian orientations and traditional gender-role beliefs and attended religious services more frequently. Implications for educators in the university environment and the classroom are presented.
\end{abstract}

\section{Keywords}

attitudes toward lesbians and gay men, attribution theory, religiosity, same-sex relationships, undergraduates

Gays and lesbians must endure forms of institutionalized bias in many societal organizations. Although social workers are supposed to treat clients equitably and challenge heterosexism, there are signs that many professionals fail to do so (Berkman \& Zinberg, 1997; Liddle, 1999; O'Hare, William, \& Ezoviski, 1996; Ryan, 2000). For example, studies have contended that social workers have difficulty offering competent and supportive services to gays, lesbians, and bisexuals when they maintain a negative stance toward homosexuals (Barrett \& McWhirter, 2002; Berkman \& Zinberg, 1997; Krieglstein, 2003; O’Hare et al., 1996; Saulnier, 2002; Wiener \& Siegel, 1990). Likewise, it has been found that psychologists with homophobic leanings are less likely to accept gay or lesbian clients into their caseloads (Wiener \& Siegel, 1990) and that homophobic feelings seem to interfere with effective assessments of clients and the choice of appropriate treatment goals or counseling techniques (Berkman \& Zinberg, 1997; O’Hare et al., 1996; Ryan, 2000).

\footnotetext{
'Morehead State University, Kentucky

${ }^{2}$ Ohio State University, Columbus

Corresponding Author:

Eric Swank, Department of Sociology, Social Work, and Criminology, Morehead State University, 322 Rader Hall, Morehead, KY 4035I.

Email: e.swank@morehead-st.edu
} 
In addressing issues of sexual biases among future social workers, the study presented in this article focused on students' attitudes toward gay men and lesbians. In doing so, it concentrated on the following questions: (a) What are the attitudes toward lesbians and gay men? and (b) What factors predict positive attitudes toward gay men and lesbians?

\section{Previous Research}

Our theorizing began with the premises of the social learning and human ecological perspectives (Bandura, 1977; Bronfenbrenner, 1977). Although these approaches are not identical, both frameworks emphasize that one's actions are partially a result of observing the actions of people who surround one. Subsequently, we assumed that people internalize cultural scripts and make adjustments to their own behaviors in light of the cues they receive in their social environment. Moreover, although we realize that individuals can influence familial, economic, or educational subsystems, we were especially interested in how specific social contexts shape the sentiments and behaviors of individuals. In addition, this work was informed by feminist and queer theories that suggest that the stigmatization of gays and lesbians is inevitably linked to issues of gender identities, male privilege, and heterosexism. Thus, we began our study with the assumption that homosexuality is often viewed as a disruption of "mainstream" gender roles and that heterosexist ideologies deny, trivialize, and denigrate any nonheterosexual form of behavior, identities, or relationships.

\section{Demographic Characteristics and University Context}

A person's social status can be linked to comfort with gays, lesbians, and bisexuals. Studies of the general U.S. population have found that female, white, and younger respondents have a greater tendency to accept homosexuals. However, such differences may not be as pronounced in social work circles. Some studies have found a gap in homophobic attitudes by gender, race, and youth among social work students (Cluse-Tolar, Lambert, Ventura, \& Pasupuleti, 2004; Newman, Dannenfelser, \& Benishek, 2002; Oles, Black, \& Cramer, 1999; Snively, Krueger, Stretch, Watt, \& Chandha, 2004), whereas others have not found any substantial differences for these predictor variables (Berkman \& Zinberg, 1997; Cramer, 1997; Green, 2005; Ryan, 2000).

Although social work programs generally try to eliminate prejudices among their students, the ability of college curricula to lessen homophobia is far from clear. Universal measures of years in college have sometimes found that juniors and seniors are less homophobic than freshmen (Cluse-Tolar et al., 2004; Hewitt \& Moore, 2002; Krieglstein, 2003; Oles et al., 1999), whereas other studies have found no such difference (Ben-Ari, 1998; Berkman \& Zinberg, 1997; Ryan, 2000).

\section{Individual Belief Systems and Attitudes of Significant Others}

Certain ideological beliefs seem to be linked with hostility toward gay men and lesbians. One such belief, authoritarianism, as reflected by a reverence for traditional values and the condemnation of nonconformists, has been associated with prejudice against gays and lesbians (Altemeyer \& Hunsberger, 1992; Eldridge, Mack, \& Swank, 2006; Laythe, Finkel, \& Kirkpatrick, 2001; Whitley \& Ægisdóttir, 2000; Wilkinson, 2004). Because homosexuality is often derided as a violation of traditional gender roles, those who support conventional gender prescriptions tend to express more negative attitudes (Green, 2005; Schulte, 2002). Thus, students who favor an adherence to the most stereotypical images of femininity and masculinity are often the ones who seem most disturbed by homosexuality (Basow \& Johnson, 2000; Herek, 1988; Hinrichs \& Rosenberg, 2002; Whitley \& Ægisdóttir, 2000). 
Attribution theory contends that people are more sympathetic to the disenfranchised when they believe that these individuals' plight is a result of forces beyond their control (conversely, the disenfranchised are subject to harsher criticism when others think that these persons somehow provoked their own hardship). In the case of homosexuality, people are more intolerant when they think that others choose to become gay or lesbian. Conversely, those who believe that sexual orientation is due to "genes or nature" seem more accepting of homosexuals (Furnham \& Taylor, 1990; Hegarty \& Pratto, 2001; Schulte, 2002; Wood \& Bartkowski, 2004).

In using social learning theory, Herek (1984) suggested that the messages of significant others can sway students' attitudes toward homosexuals. Although many institutions and citizens act as socializing agents, the crucial referents seem to be peers and family members. Studies of undergraduate students have often found a strong correspondence between the respondents' and peers' attitudes on matters of homosexuality (Herek, 1988; Schulte, 2002). Similarly, studies have detected a relationship between the sexual prejudice of parents and that of their children (Cossman, 2004; Kulik, 2004; Newman et al., 2002; O’Bryan, Fishbein, \& Ritchey, 2004).

\section{Contact With Homosexuals}

Allport's contact hypothesis suggests that intergroup contact, especially contact with people of equal statuses can reduce prejudices toward oppressed group members (cited in Herek \& Glunt, 1993). Individuals who reported more contact and positive experiences with lesbians and gay men have consistently expressed greater acceptance of homosexuals (Barrett \& McWhirter, 2002; Berkman \& Zinberg, 1997; Herek, 1988; Hinrichs \& Rosenberg, 2002; Krieglstein, 2003; Newman et al., 2002; O'Hare et al., 1996; Oles et al., 1999; Plugge-Foust \& Strickland, 2000; Snively et al., 2004). Although conversations with gay men and lesbians of any age or profession seem to lessen animosities, some studies have confirmed that heterosexual college students display the greatest attitudinal change when they meet other students who are gay or lesbians (Barrett \& McWhirter, 2002; Eldridge et al., 2006; Oles et al., 1999; Schope \& Eliason, 2000; Wood \& Bartkowski, 2004).

\section{Religiosity}

Despite variability in the measurement of religiosity, a relationship between religiosity and negative attitudes toward gay men and lesbians has been demonstrated. Christian ideology has been found to be the strongest predictor of homophobic attitudes among college students (Plugge-Foust \& Strickland, 2000; Snively et al., 2004), and religious fundamentalism has been associated with negative attitudes toward members of the gay community (Altemeyer \& Hunsberger, 1992; Krieglstein, 2003; Newman et al., 2002; Ryan, 2000; Wood \& Bartkowski, 2004), as has belonging to a conservative denomination and attending religious services more frequently (Cluse-Tolar et al., 2004; Cramer, 1997; Herek \& Glunt, 1993). Furthermore, many of these qualities of religiosity have been found to predict homophobia among social work students (Newman, 2002; Newman et al., 2002) and employed social workers (Berkman \& Zinberg, 1997; Ryan, 2000).

\section{Method}

The cross-sectional study presented here began with a stratified sampling technique. Every accredited bachelor of social work program in the United States functioned as the sampling unit (schools were identified through the Web site of the Association of Baccalaureate Social Work Program Directors, 2004). To pursue geographic diversity, the regional divisions of the U.S. Census Bureau were used to separate programs into nine regional groups. Two programs were randomly selected from each stratum (originally 18 schools were selected). 
Prior to the start of the 2004 academic year, we identified faculty members who were scheduled to teach the introductory and senior-level social work courses. Every identified faculty member received an e-mail describing the study and a follow-up telephone call. Faculty members from 2 of the 18 programs declined to participate, and an additional 2 programs had institutional requirements related to their human subjects' board that precluded their participation. Thus, faculty members from 14 of the original 18 programs agreed to participate in the study. A packet of questionnaires were mailed to all the faculty members who were asked to distribute them within the first 2 weeks of the quarter or semester, in an attempt to reduce the potential bias of students' responses because of the course content. A script was provided to every faculty member, which relayed the purpose of the study and a reminder that participation was anonymous and purely voluntary. The faculty members were instructed to leave the room and return the completed surveys in a sealed envelope. Data collection occurred one time for each course, and no incentives were offered to either the faculty members or the students for their participation.

Surveys were returned by 747 students from 12 institutions. Because our measure of the criterion variable is appropriate only for use with heterosexuals, the final sample was restricted to the 629 students who self-identified as "completely heterosexual." Because of missing data from 54 students, the final sample consisted of 575 students. With regard to the geographic dispersion of the students, there were 67 students from schools in the Northeast, 228 students from schools in the Midwest, 191 students from schools in the South, and 89 students from schools in the West. Eleven of the 12 participating academic institutions were classified as public, and 1 was private, not for profit, with no religious affiliation (Carnegie Foundation for the Advancement of Teaching, 2006). With regard to the demographic distribution of the sample, more than three fourths of the students were Euro-American $(n=450)$ and female $(n=493)$. The respondents ranged in age from 18 to 73 , with a mean of 24 , and $80 \%$ were aged 18-26. The majority of the respondents were social work or presocial work students $(62.5 \%$ ), with $32.9 \%$ expecting to earn their Bachelor of Social Work (BSW) degrees during the year of participation in the study. The final sample $(n=575)$ did not differ significantly from the total potential participants $(n=747)$ with regard to age, gender, or race.

\section{Measures}

Fifteen variables were used for the research. Both criterion variables and four of the predictors were multiitem scales. The names of the scale and their reliability coefficients were as follows: Attitudes Toward Lesbians (.843), Attitudes Toward Gay Men (.920), Authoritarianism (.647), Gender-Role Beliefs (.670), Parental Acceptance of Homosexuality (.735), and Attribution of Cause (.797). The nine single-item predictors were gender, race, age, graduating social work student, social work student in the introductory course, close friend contact, school acquaintance contact, friend's acceptance of homosexuality, and frequency of attendance at religious services.

Criterion variables. In tracking our dependent variable, we used the Attitudes Toward Lesbians and Gay Men (ATLG) scale. This 10-item scale taps a heterosexual's affective responses to gay men and lesbians (Herek, 1988). The ATLG is used widely in studies of social workers (see, e.g., Ellis, Kitzinger, \& Wilkinson, 2002; Green, 2005; Newman et al., 2002; Oles et al., 1999) and was developed through an extensive factor analysis and numerous construct validity studies (Herek, 1988). We separated the broader ATLG into the Attitudes Toward Lesbians (ATL) and the Attitudes Toward Gays (ATG) subscales (the verbatim wording of the items is presented in Table 1). Higher composite scores reflect greater levels of sexual prejudice (with both the ATG and ATL offering a potential range of 5-25). 
Table I. Frequencies and Percentages for Responses to the Attitudes Toward Lesbians and Attitudes Toward Gay Men Subscales

\begin{tabular}{|c|c|c|c|c|c|c|}
\hline Responses & $\begin{array}{l}\text { Strongly } \\
\text { Disagree }\end{array}$ & Disagree & Neutral & Agree & $\begin{array}{l}\text { Strongly } \\
\text { Agree }\end{array}$ & $M(S D)$ \\
\hline $\begin{array}{l}\text { Lesbians just cannot fit into our } \\
\text { society }\end{array}$ & $271(47.3)$ & I78 (3I.I) & $76(13.3)$ & $30(5.2)$ & $18(3.1)$ & $1.86(1.04)$ \\
\hline $\begin{array}{l}\text { State laws regulating private, } \\
\text { consenting lesbian behavior } \\
\text { should be loosened (mean } \\
\text { recoded) }\end{array}$ & $71(12.5)$ & $88(15.5)$ & $182(32.1)$ & |4| (24.9) & $85(15.0)$ & $2.86(1.22)$ \\
\hline Female homosexuality is a $\sin$ & $180(3 \mid .5)$ & $91(15.9)$ & $84(14.7)$ & $84(14.7)$ & $133(23.3)$ & $2.82(1.57)$ \\
\hline $\begin{array}{l}\text { Female homosexuality in itself is no } \\
\text { problem, but what society makes } \\
\text { of it can be a problem (mean } \\
\text { recoded) }\end{array}$ & $81(14.3)$ & $78(13.8)$ & $65(11.5)$ & $236(4 I .6)$ & $107(18.9)$ & $2.63(1.32)$ \\
\hline Lesbians are sick & $268(46.7)$ & $135(23.5)$ & $100(17.4)$ & $34(5.9)$ & $37(6.4)$ & $2.02(1.21)$ \\
\hline $\begin{array}{l}\text { I think male homosexuals are } \\
\text { disgusting }\end{array}$ & $225(39.2)$ & $129(22.5)$ & $89(15.5)$ & $58(10.1)$ & $73(12.7)$ & $2.35(1.41)$ \\
\hline Male homosexuality is a perversion & $211(37.2)$ & $94(16.6)$ & $110(19.4)$ & $76(13.4)$ & $76(13.4)$ & $2.49(1.44)$ \\
\hline $\begin{array}{l}\text { Just as in other species, male } \\
\text { homosexuality is a natural } \\
\text { expression of sexuality in men } \\
\text { (mean recoded) }\end{array}$ & $111(19.4)$ & $91(15.9)$ & $136(23.7)$ & $152(26.5)$ & $83(14.5)$ & $2.99(1.33)$ \\
\hline $\begin{array}{l}\text { Homosexual behavior between two } \\
\text { men is just plain wrong }\end{array}$ & $172(30.1)$ & $109(19.1)$ & $89(15.6)$ & $86(15.0)$ & $116(20.3)$ & $2.76(1.52)$ \\
\hline $\begin{array}{l}\text { Male homosexuality is merely a } \\
\text { different kind of life style that } \\
\text { should not be condemned } \\
\text { (mean recoded) }\end{array}$ & $87(15.2)$ & $80(14.0)$ & $98(17.1)$ & I55 (27.I) & $153(26.7)$ & $2.64(1.40)$ \\
\hline ATL subscale & & & & & & $12.17(5.00)$ \\
\hline ATG subscale & & & & & & $13.20(6.18)$ \\
\hline
\end{tabular}

Note: High scores equal negative attitudes. ATL $=$ Attitudes Toward Lesbians, ATG $=$ Attitudes Toward Gays.

Predictor variables. Gender-role beliefs were examined with a 5-item Likert scale that used items from the Attitudes Toward Sexual Coercion and Assault subscale of the Attitudes Toward Sexuality Inventory (Patton \& Mannison, 1995), an item from the Attitudes Toward Women scale (Spence, Helmreich, \& Stapp, 1973, cited in Swim \& Cohen, 1997), and an item from a study on marital satisfaction (Lye \& Biblarz, 1993). These items deal with the perception of sexism in the workforce, the proper division of labor in families, and double standards about female sexuality (a higher score represents a greater reverence for traditional gender-role beliefs). For authoritarianism, we borrowed three items from the Right Wing Authoritarianism scale (Altemeyer, 1988); a higher score represents greater support for submission to authority figures and anger toward dissenters. Friend acceptance was measured with one 5-point Likert item, "My friends are generally accepting of homosexuals" (higher scores suggest positive attitudes among friends). Parental acceptance was identified by two items that stated that either my mother or my father "believes that homosexuality is wrong" (rejection of these statements receives higher scores). Attribution of cause was gauged by two items on a 5-point "choice" scale (Hegarty \& Pratto, 2001; Wood \& Bartkowski, 2004). One item stated that "people choose to be homosexual," whereas the second stated that "homosexuality is caused by biological forces" (a higher score indicates greater belief in the choice of sexual orientation). 
Religiosity was measured with one item regarding the frequency of attendance at religious services (see Cramer, 1997; Hegarty \& Pratto, 2001; Herek, 1988; Herek \& Glunt, 1993; Hinrichs $\&$ Rosenberg, 2002). On a 4-point scale of response, the highest score, "more than once a week," represented the greatest participation in religious services, whereas "never" represented the lowest. Contact with homosexuals was measured via two dichotomous items of whether the respondents have any gay or lesbian close friends or school acquaintances (as in Herek, 1988; Wood \& Bartkowski, 2004).

\section{Results}

\section{Descriptive Findings}

Students' attitudes toward lesbians and gay men are presented in Table 1. As a whole, the distribution displayed a slightly favorable impression of gays and lesbians (the means fell between 1.86 and 2.99 for every item). Likewise, the composite means of 12.17 and 13.20 suggest that the entire sample was skewed in a slightly positive direction (although a slightly higher mean for gay men suggests that the students had some greater reservations toward gay men).

In exploring each item, we found some general trends. When we collapsed the strongly agree and agree categories, we found that more than three fourths of the students agreed that lesbians are able to fit into society. In addition, more than two thirds disagreed that lesbians are sick, and more than half agreed that society creates the problems associated with lesbians and disagreed that gay men are disgusting or that male homosexuality is a perversion that should be condemned. The items that generated the greatest polarization of responses were related to loosening state laws that regulate private, lesbian behavior ( $28 \%$ disagreed and $39.9 \%$ agreed) and male homosexuality being a natural expression of sexuality (35.3\% disagreed and $41 \%$ agreed). Thus, most of the students saw no pathological side to homosexuality, most did not think that being lesbian was deviant, and half wanted to liberalize laws against homosexuality.

In comparing these findings to studies of the general U.S. population, we found that these social work undergraduates were relatively less homonegative. The random sample of Herek and Glunt (1993) found that adults were twice as likely as the students in our sample to think that "male homosexuals are disgusting" or that "homosexual behavior between two men is just plain wrong." Conversely, the students in our study were less receptive to gays and lesbians than were students in other human service majors. For example, $13.6 \%$ of the undergraduate psychology students in the study of Ellis et al. (2002) versus $35.4 \%$ of the BSW students in our study considered homosexuality an unnatural expression. Likewise, the BSW students were more than three times as likely as the psychology students to think that "lesbians cannot fit into society," "lesbians are sick," and "gays are disgusting." The findings of the study of Newman et al. (2002) suggest an even larger discrepancy between undergraduate and graduate social work students. That is, $53 \%$ of the BSW students in our study, but $16 \%$ of the Master of Social Work (MSW) students in the study of Newman et al. disagreed that homosexuality is merely a different kind of lifestyle. Similarly, $38 \%$ of the BSW students versus $16 \%$ of the MSW students study thought that homosexuality is a sin.

\section{Findings of the Multivariate Analysis}

The results of the hierarchical ordinary least squares regressions for the ATL and ATG are presented in Table 2 (Step 1 is for the demographic factors and Step 2 is for the entire model). As a whole, the demographic variables in Model 1 contributed a minimal $5.4 \%$ and $6.7 \%$ of the variance for both criterion variables (as indicated by the $R^{2}$ ). Only race was significant in the first step for both the ATL and ATG (the Euro-American students displayed greater acceptance of both gays and lesbians when the demographic factors were controlled). However, the rest of the demographic factors did 
Table 2. Hierarchical Regressions for the Attitudes Toward Lesbians $(n=554)$ and Attitudes Toward Gays $(n=560)$ Subscales

\begin{tabular}{|c|c|c|c|c|c|c|}
\hline \multirow[b]{2}{*}{ Predictor Variables } & \multicolumn{3}{|c|}{ Attitudes Toward Lesbians } & \multicolumn{3}{|c|}{ Attitudes Toward Gays } \\
\hline & B & $S E B$ & $\beta$ & B & $S E B$ & $\beta$ \\
\hline \multicolumn{7}{|l|}{ Model I } \\
\hline Gender $(I=$ male $)$ & -.03 & .60 & -.00 & 1.88 & .74 & $.11 *$ \\
\hline Race $(\mathrm{I}=$ Caucasian $)$ & -1.89 & .51 & $-.15 * * *$ & -2.81 & .62 & $-.19 * * * k$ \\
\hline Age & .02 & .03 & .03 & .04 & .03 & .05 \\
\hline Senior social work student & -1.29 & .51 & $-.12^{* *}$ & -1.12 & .63 & -.09 \\
\hline Introductory social work student & .84 & .51 & .08 & .46 & .63 & .03 \\
\hline$R^{2}$ & .05 & & & .07 & & \\
\hline \multicolumn{7}{|l|}{ Model 2} \\
\hline Gender $(I=$ male $)$ & -1.03 & .39 & $-.07 * *$ & .41 & .47 & .02 \\
\hline Race & .22 & .33 & .02 & -.42 & .38 & -.03 \\
\hline Age & .00 & .02 & .01 & .03 & .02 & .03 \\
\hline Senior social work student & -1.19 & .33 & $-.11 * * *$ & -.96 & .39 & $-.07^{*}$ \\
\hline Introductory social work student & -.03 & .32 & -.00 & $-.4 \mathrm{I}$ & .38 & -.03 \\
\hline Authoritarianism Scale & .16 & .06 & $.08 * *$ & .16 & .07 & $.06 *$ \\
\hline Traditional gender role & .21 & .06 & $.11 * * *$ & .29 & .07 & $.12 * * *$ \\
\hline Parental homosexual acceptance & -.44 & .07 & $-.20 * * *$ & -.70 & .08 & $-.26 * * * *$ \\
\hline Friend homosexual acceptance & -.61 & .14 & $-.14^{* * * *}$ & -.79 & .16 & $-.14 * * * *$ \\
\hline Homosexual close friend & -.15 & .30 & -.01 & -.34 & .36 & -.03 \\
\hline Homosexual school acquaintance & -.64 & .30 & $-.06 *$ & -.73 & .35 & $-.06 *$ \\
\hline Frequency of religious attendance & 1.43 & .15 & $.30 * * *$ & 1.29 & .17 & $.22 * * * *$ \\
\hline Attribution of cause (choice) & .70 & .07 & $.33 * * *$ & .91 & .08 & $.34 * * *$ \\
\hline$R^{2}$ & .64 & & & .67 & & \\
\hline
\end{tabular}

$* p<.05$.

$* * p<.01$.

$* * * p<.001$.

not fair so well in these initial calculations. In Step 1 of the ATG, class standing and age had little relevance, whereas gender reached significance (the male students showed greater homophobia). In Step 1 of the ATL, significance was limited to the year in college, whereas age and gender had little relevance. It is interesting to note that the change of direction in and the significance of the gender variable may suggest that male students are much harsher on gay men than on lesbians.

When we added every variable to the final regression, we found that the full model was more potent (see Model 2). At a broad level, the amount of variance explained by the full model jumped dramatically in both cases (for the ATL, the $R^{2}$ increased from .05 to .64 and the ATG coefficient of determination increased from .07 to .67). In addition, the inclusion of new variables altered the impact of the previously significant variables. Race lost its importance in the final model for both the ATL and ATG, whereas senior standing displayed consequential associations in the last regressions. Gender was unique in that it increased in significance in the ATL and disappeared in the ATG (the directionality of the coefficients still suggests that male students are more hostile to gays than to lesbians). However, even with some demographic factors retaining significance in the final model, it is clear that their $\beta$ coefficients are far lower than those of the new factors.

Seven of the eight contextual and ideological variables reached significance in both final regressions. Attributions for cause had the largest coefficient in each model (.33 and .34). Students who ascribed sexual orientation to "choice" were more negative toward lesbians and gay men. The coefficients for religious attendance and parental attitudes were also among the three most important 
predictors in all the final models ( -.20 to .30$)$. Students who believed that their friends condoned homosexuality and those who distanced themselves from authoritarianism and traditional gender expectations were more sympathetic to gay men and lesbians (the $\beta$ ranged from.11 to -.26). Finally, interacting with gay or lesbian acquaintances at school lessened negative attitudes, but having a gay or lesbian close friend was not deemed as important.

Finally, the educational variable had different impacts for gays and lesbians. Although greater support of gays and lesbians were generally discovered among the seniors, the variable senior standing reached significance only for the ATL. This finding suggests that the educational environment may be less adept at facilitating the acceptance of gay men. With male students being significantly more tolerant of lesbians than of gays, it is possible that the social work programs are less effective in helping male students overcome their strong prejudices against gay men.

\section{Limitations of the Study}

The representativeness of the sample is difficult to judge for a number of reasons. First, although the sampling strategy was modeled on probability sampling, there may have been some selection biases among the schools that decided to opt out the study. Second, the anonymous nature of data collection prohibited any type of nonresponse analysis (we could not tell whether any types of students decided to forgo this survey at higher rates). Third, students also self-select when enrolling in a social work course, and this study's findings may not fully reflect the ideas of students in other academic majors. Even with these sampling caveats, this study included the perspectives of undergraduate social work students with different levels of education, who were matriculating at many institutions across the United States.

The cross-sectional design created some drawbacks as well. Because the data were gathered only once, the survey items could been subject to problems of overdemanding recall or social desirability (people may not remember what their parents thought about homosexuals or may alter their memories of parental values to suit their current attitudes). Likewise, issues of temporal ordering may be confusing and problematic (it is possible that homophobic students pick homophobic friends). As for measurement errors, the use of existing instruments and the high Cronbach's $\alpha$ suggest acceptable levels of reliability. However, the wording of certain items can always undermine the validity of measures (e.g., the issue of "knowing" a person's sexual orientation may be misleading, because most heterosexuals and homosexuals do not explicitly identify their sexual orientation). Moreover, our educational measures could have been too universal. That is, the educational factors could have presented a larger impact if we measured some aspects of class content (rather than how many classes a student has finished). In addition, subtler educational measures may explain our anomalous finding of the significance of senior standing only for the ATL. Finally, the ATL and ATG and our measures of gender expectations and authoritarianism could have ignored some important dimensions of these concepts.

\section{Discussion}

Van Den Bergh and Crisp (2004) described the history of, and rationale for, social work's mandate to offer culturally competent practice for sexual minorities. Their use of the attitudes, knowledge, and skills trilogy is applicable to this study. The knowledge dimension seems important, because attending extra classes seems to lessen hostility toward lesbians (assuming that classes impart knowledge to students). Nevertheless, knowledge by itself does not seem to be the strongest correlate of sexual biases. Many of the extracurricular factors displayed stronger associations, and senior standing did not reach significance for the ATG. The acceptance of homosexuality by family members and friends, as well as the opposition to traditional gender roles and less authoritarianism, was important 
predictors of supportive attitudes. Thus, the university environment and course content alone may not fully undo what students have internalized from parents, friends, and religion. Nevertheless, the completion of classes seems to act as a mild suppressant of homophobia (significant only for attitudes toward lesbians though). Likewise, the data offer some clues to important class content. The association between gender roles and sexual prejudices suggests that classes that debunk gender inequities may indirectly lessen some condemnations of gay men and lesbians. Or stated otherwise, students may be more inclined to scrutinize heterosexism after their teachers probe the assumptions of compulsorily heterosexuality in dating or the amount of institutionalized male privilege in families and workplaces. Likewise, curricula that ask students to move beyond a reverence for authority figures may decrease negative attitudes toward gay men and lesbians. However, with gender being significant for the ATL, it is possible that the effectiveness of discussions of gender inequalities and authoritarianism may be different for male and female students.

Similarly, the attitudinal factors of attribution of choice and religiosity presented some of the largest associations. Although discussions of religious tenets may be seen as outside the purview of most secular universities, colleges can create classes that address the similarities and differences between professional and religious perspectives on sexuality. Regardless of whether these differences are addressed, it seems wise to insist that religious objections should not justify the exclusion of course content on sexual orientation. Fletcher and Russell (2001) suggested that students who are concerned that course content conflicts with their religious beliefs should be reminded that students are traditionally required to study material that may not be consistent with their personal backgrounds.

Faculty and administrators can do things that alter the immediate collegiate environment. For example, they can create "hate-free" zones that offer a safe and welcoming space for gay and lesbian students. Doing so would display proper professional behaviors and possibly foster a higher percentage of publicly "out" faculty, students, and staff members. Our data suggest that this greater number of "out" members of the gay community may decrease the extent of sexual prejudice among heterosexual students (having a gay or lesbian school acquaintance was significant). Regardless of what steps educators take in this direction, it is clear that they must keep working on this process, because future social workers must be armed with the knowledge and skills to pursue the social justice goals of the profession.

Future research can use this information in several ways. First, researchers may want to apply these important variables to samples of employed workers or social work faculty. Second, they may want to explore the relationship between attitudes toward gays and lesbians and the practice routines or political behaviors of human service professionals (see Crisp, 2006). Finally, longitudinal studies that measure students' attitudes during their entire university careers could add nuanced understandings of long-term effects of the college setting. Most important, studies that follow the subsequent careers of social work students could fill a crucial void. It is only through such studies that we can gain an accurate grasp of what educational experiences subsequently guide the daily practices of employed social workers (see Oles et al., 1999; Swank \& Raiz, 2008).

\section{References}

Altemeyer, B. (1988). Enemies of freedom. San Francisco: Jossey-Bass.

Altemeyer, B., \& Hunsberger, B. (1992). Authoritarianism, religious fundamentalism, quest, and prejudice. International Journal for the Psychology of Religion, 2, 113-133.

Association of Baccalaureate Social Work Program Directors. (2004). Accredited BSW programs. Retrieved

November 2, 2009, from http://www.bpdonline.org/Accredited_BSW-Programs

Bandura, A. (1977). Social learning theory. New York: General Learning Press. 
Barrett, K., \& McWhirter, B. (2002). Counselor trainees' perceptions of clients based on client sexual orientation. Counselor Education \& Supervision, 41, 219-232.

Basow, S. A., \& Johnson, K. (2000). Predictors of homophobia in female college students. Sex Roles, 42 , 391-404.

Ben-Ari, A. T. (1998). An experimental attitude change: Social work students and homosexuality. Journal of Homosexuality, 36, 59-71.

Berkman, C. S., \& Zinberg, G. (1997). Homophobia and heterosexism in social workers. Social Work, 42, 319-332.

Bronfenbrenner, U. (1977). Toward an experimental ecology of human development. American Psychologist, 32, 513-531.

Carnegie Foundation for the Advancement of Teaching. (2006). Institution lookup. Retrieved May 13, 2006, from http://www.carnegiefoundation.org/classifications/index.asp?key $=782$

Cluse-Tolar, T., Lambert, E., Ventura, L., \& Pasupuleti, S. (2004). The views of social work students toward gay and lesbian persons. Journal of Gay \& Lesbian Social Services, 17, 59-84.

Cossman, J. S. (2004). Parents' heterosexism and children's attitudes toward people with AIDS. Sociological Spectrum, 24, 319-339.

Cramer, E. (1997). Effects of an educational unit about lesbian identity development and discloser in a social work methods course. Journal of Social Work Education, 33, 467-479.

Crisp, C. (2006). The gay affirmative practice scale (GAP). Social Work, 51, 115-126.

Eldridge, V., Mack, L., \& Swank, E. (2006). Explaining comfort with homosexuals in rural America. Journal of Homosexuality, 51, 39-56.

Ellis, S. J., Kitzinger, C., \& Wilkinson, S. (2002). Attitudes toward lesbians and gay men and support for lesbian and gay human rights among psychology students. Journal of Homosexuality, 44, 121-138.

Fletcher, A. C., \& Russell, S. T. (2001). Incorporating issues of sexual orientation in the classroom: Challenges and solutions. Family Relations, 50, 34-40.

Furnham, A., \& Taylor, L. (1990). Lay theories of homosexuality. British Journal of Social Psychology, 29, 135-147.

Green, R. (2005). The use of two-dimensional social scale to assess social worker's attitudes toward lesbians and gay men. Social Work Research, 29, 57-60.

Hegarty, P., \& Pratto, F. (2001). Sexual orientation beliefs: Their relationship to anti-gay attitudes and biological determinist arguments. Journal of Homosexuality, 41, 121-135.

Herek, G. M. (1984). Attitudes toward lesbians and gay men: A factor analytic study. Journal of Homosexuality, 10(1/2), 39-51.

Herek, G. M. (1988). Heterosexuals' attitudes toward lesbians and gay men: Correlates and gender differences. Journal of Sex Research, 25, 451-477.

Herek, G. M., \& Glunt, E. K. (1993). Interpersonal contact and heterosexuals' attitudes toward gay men: Results from a national survey. Journal of Sex Research, 30, 239-244.

Hewitt, E., \& Moore, L. (2002). The role of lay theories about the etiologies of homosexuality in attitudes toward lesbians and gay men. Journal of Lesbian Studies, 6, 59-72.

Hinrichs, D. W., \& Rosenberg, P. J. (2002). Attitudes toward gay, lesbian, and bisexual persons among heterosexual liberal arts college students. Journal of Homosexuality, 43, 61-84.

Krieglstein, M. (2003). Heterosexism and social work. Journal of Human Behavior in the Social Environment, 8, 75-91.

Kulik, L. (2004). Transmission of attitudes regarding family life from parents to adolescents in Israel. Families in Society, 85, 345-353.

Laythe, B., Finkel, D., \& Kirkpatrick, L. A. (2001). Predicting prejudice from religious fundamentalism and right-wing authoritarianism. Journal for the Scientific Study of Religion, 40, 1-10.

Liddle, B. (1999). Gay and lesbian client's ratings of psychiatrist, psychologists, social workers and counselors. Journal of Gay and Lesbian Psychotherapy, 3, 81-93. 
Lye, D. N., \& Biblarz, T. J. (1993). The effects of attitudes toward family life and gender roles on marital satisfaction. Journal of Family Issues, 14, 157-188.

Newman, B. S. (2002). Lesbians, gays and relief systems. Journal of Lesbian Studies, 6, 87-98.

Newman, B. S., Dannenfelser, P. L., \& Benishek, L. (2002). Assessing beginning social work and counseling students' acceptance of lesbians and gay men. Journal of Social Work Education, 38, 273-288.

O’Bryan, M., Fishbein, H. D., \& Ritchey, P. N. (2004). Intergenerational transmission of prejudice, sex role stereotyping, and intolerance. Adolescence, 39, 407-426.

O’Hare, T., Williams, C. L., \& Ezoviski, A. (1996). Fear of AIDS and homophobia: Implications for direct practice and advocacy. Social Work, 41, 51-58.

Oles, T., Black, B., \& Cramer, E. (1999). From attitude change to effective practice. Journal of Social Work Education, 35, 1043-1057.

Patton, W., \& Mannison, M. (1995). Sexuality attitudes: A review of the literature and refinement of a new measure. Journal of Sex Education and Therapy, 21, 268-295.

Plugge-Foust, C., \& Strickland, G. (2000). Homophobia, irrationality, and Christian ideology: Does a relationship exist? Journal of Sex Education \& Therapy, 25, 240-244.

Ryan, S. (2000). Examining social workers' placement recommendations of children with gay and lesbian adoptive parents. Families in Society, 81, 517-528.

Saulnier, C. F. (2002). Deciding who to see: Lesbians discuss their preferences in health and mental health providers. Social Work, 47, 355-365.

Schope, R. D., \& Eliason, M. E. (2000). Thinking versus acting: Assessing the relationship between heterosexual attitudes and behaviors toward homosexuals. Journal of Gay \& Lesbian Social Services, 11, 69-91.

Schulte, L. (2002). Similarities and differences in homophobia among African Americans and Caucasians. Race, Gender \& Class, 9, 71-93.

Snively, C., Krueger, L., Stretch, J., Watt, J., \& Chandha, J. (2004). Understanding homophobia: Preparing for practice realities in urban and rural settings. Journal of Gay and Lesbian Social Services, 17, 59-79.

Spence, J. T., Helmreich, R., \& Stapp, J. (1973). A short version of the Attitudes Toward Women Scale. Bulletin of the Psychonomic Society, 2, 219-220.

Swank, E., \& Raiz, L. (2008). Attitudes toward lesbians of practicing social workers and social work students. Journal of Baccalaureate Social Work, 13, 55-69.

Swim, J. K., \& Cohen, L. L. (1997). Overt, covert, and subtle sexism. Psychology of Women Quarterly, 21, 103-118.

Van Den Bergh, N., \& Crisp, C. (2004). Defining culturally competent practice with sexual minorities: Implications for social work education and practice. Journal of Social Work Education, 40, 221-238.

Whitley, B. E., \& Egisdóttir, S. (2000). The gender belief system, authoritarianism, social dominance orientation, and heterosexuals' attitudes toward lesbians and gay men. Sex Roles, 42, 947-967.

Wiener, L., \& Siegel, K. (1990). Social workers' comfort in providing service to aids patients. Social Work, 35, $18-26$.

Wilkinson, W. W. (2004). Religiosity, authoritarianism, and homophobia. International Journal for the Psychology of Religion, 14, 55-67.

Wood, P. B., \& Bartkowski, J. P. (2004). Attribution style and public policy attitudes toward gay rights. Social Science Quarterly, 85, 58-74.

\section{Bios}

Eric Swank, PhD, is an associate professor in the Department of Sociology, Social Work, and Criminology, Morehead State University, 322 Rader Hall, Morehead, KY 40351; e-mail: e.swank@morehead-st.edu.

Lisa Raiz, $\mathrm{PhD}$, is an associate professor in the College of Social Work, Ohio State University, Stillman Hall, 1947 College Road, Columbus, OH 43210; e-mail: raiz.1@osu.edu. 